the city of London will, no doubt, be watched with interest, and taken as a guide, by the local authorities of other parts of the metropolis.

\section{THE WINSLOW CASE.}

Mr. Josepr J. Pope, the " medical assessor" at the late trial of Regina $v$. Winslow, has published a brochure, in which he announces his "anxiety to express what appears to him the perfect justification of the acquittal of the prisoner," arising out of circumstances which "throw great doubt upon the medical evidence that the death of Ann James was accelerated by the action of antimony." He maintains that the symptoms during life and the appearances after death were compatible with existing natural disease, and concludes that the theory of "acceleration" of death was solely based upon the detected presence of antimony, and not upon its observed effects. The purging Mr. Pope connects with the disease of the bowels; the vomiting with the cancerous state of the stomach, the character of the vomiting according with the anatomical site of the ulcer. The "remarkable intermission" he attributes, not to any break in the administration of poison, but, on the strength of a quotation from Dr. Watson, claims it as "a curious feature in malignant diseases of the stomach." Negatively, Mr. Pope points out there was no antimonial rash or congestion of the lungs and other soft vascular organs. But then, to admit the presence of the poison, and yet to admit its want of action, requires also a theory. This Mr. Pope has ready at hand, in a doctrine of toleration, especially " at certain crises, when antimony might be present in the human frame without producing injurious resuits." Altogether, Mr. Pope's brochure is an interesting and ably-thonght argument upon antimonial poisoning-a subject still of great interest in medical jurisprudence. But it is inconclusive almost in the same degree that it is ingenious. ts perusal has brought us to precisely opposite conclusions from those at which the author arrives.

\section{HOUSES OF ILL-HEALTH.}

THERE is one way to make homes unhealthy which has often been criticized by our Medical Officers of Health, and which still demands all their vigilance to prevent. It forms a regular part of building operations in many localities around London. You may ventilate a house and drain the street; supply plenty of light, air, and fresh water; but there may still be a source of disease in your house which may elude discovery, and if discovered defy remedy. It is literally bound up in the composition of the road, and forms part of the fabric of the house wall. A Scottish registrar lately noticed that the increase of fever and zymotic disease in his district was chiefly confined to a street of newly-built and somewhat superior houses. Some surgeons have from time to time made the like observation in the suburbs of London. If the composition of the roadway be observed, and the air of the basement tested, the cause may be partly guessed. It is not unusual, in making these roadways, to cast into the chasm to be filled every kind of refuse, including animal and vegetable débris of the most unsavoury character; and this being packed together on a level with the basement, all emanations from the mass steal through the lower part of the house and ascend to the upper rooms. A surgeon in the sonthern suburb communicated to us a case in which the members of a numerous family were successively attacked by zymotic disease-in two instances fatal, and repeatedly renewed, until removal from a house so poisoned. Dr. Dundas Thomson, in his weekly report, draws attention to a cognate defect in the hygienies of masonry which deserves to be duly noted:-

"My attention has frequently been called to, I trust, an almost obsolete practice indulged in by some builders, of mixing up putrid slop from the streets with their mortar, instead of using sand, which has a chemical relation to the lime. case of this kind having been reported to me by the inspectors at Hamilton-terrace, I found the slop used to consist of putrid organic matter, $8 \cdot 77$; water, $36 \cdot 6$; and of inorganic matter, 54.18. Being of opinion that the use of such a mixture in plastering the interior of a house is not likely to be promotive of health, while it undoubtedly produces an inferior binding material, I requested the builder and the architect to discontinue its use, but not in time to prevent the fall of an arch, and the injury of three men engaged in the construction of the build. ing."

\section{Ẽxtenonotite.}

"Audi alteram partem."

\section{POYSONING BY ACONITE.} To the Editor of The LaNCET.

Srr,-I send you the following account of a case of poisoning by aconite which has lately occurred in this neighbourhood. It may prove interesting to many of your readers, as forming a fresh instance of an error which has been committed more than once: I mean that of mistaking aconite-root for horse-radish. In the present case, about a pound of the root of aconitum napellus was cut into slices and mixed with a gallon of pickles. A young married woman, who partook of them the next day, was seized, within ten hours of the meal at which they were eaten, with violent spasms and severe pains, with pricking sensation in the limbs, back, and chest, difficulty of breathing, and partial loss of sight; the pulse was considerably lowered, and the skin cold and clammy. Chloric ether and ammonia were given in full doses, and in an hour or two the patient rallied. The canse of these symptoms was unexplained until the following day, when three other members of the family, (namely, the mother, sister, and brother, within an hour of having again eaten some of the pickles, were attacked in a similar manner. The mother was only slightly affected, but the brother and sister, especially the latter, who had taken a large quantity of the vinegar, suffered mnch more severely. These two patients were made to walk about; emetics were freely administered, and large quantities of brandy, ammonia, and chloric ether were given at frequent intervals; mustard ponltices were applied to the chest and back of the neck, and hot water bottles to the soles of the feet. Galvanism, by means of a Pulvermacher's chain, was also employed over the region of the heart, in the case of the sister, whose pulse was at one time imperceptible. Fully twelve hours elapsed before this patient could be pronounced out of danger. The symp. toms were much the same as in the first case, but in a more aggravated form, opisthotonos and trismus being very marked. They are now all gradually recovering their usual health, though for some days they complained of great pain and tenderness in the region of the spine, together with loss of sleep and appetite.

Hoping that, from the rarity of similar cases, this rough sketch may be worthy of a place in your valuable columns, I remain, Sir, yours obediently,

Sunninghill, Berks, Sept. 1360. JoHN Barr Brown, M.R.C.S.

\section{VERSION WITHOUT INSERTING THE HAND IN THE UIERUS.}

To the Elitor of The LANCeT.

Sin,-I think the following case so fully confirms the value of the method of turning described by Dr. B. Hicks, that I beg its insertion in your journal.

Early on the morning of July 24 th I was summoned by a midwif̂e in this neighbourhood to go over to Woking to see a young woman under her care, and who was in a dangerous state from flooding. I found the patient, a delicate person, aged twenty-eight, in labour with her fourth child, in a most critical condition; face and lips pallid; extremities cold; pulse 140 , small, and tremulous. She had had only three slight pains, but had lost a large quantity of blood. I found the vagina filled with coagula; the os uteri dilated to the size of a crown-piece, and entirely blocked up by the placenta. On passing two fingers between the wall of the uterus and the placenta, I felt a cephalic presentation, the membranes being unruptured. Knowing that no time must be lost, I determined on trying the plan of version suggested by Dr. B. Hicks. With 